\title{
Mitgliederversammlungen auf dem 99. Deutschen Röntgenkongress, 9.-12. Mai 2018
}

\author{
(unter Vorbehalt zeitlicher Änderungen, Stand 06.03.2018)
}

\begin{tabular}{|c|c|c|c|}
\hline \multirow[t]{2}{*}{$\begin{array}{l}\text { Mittwoch } \\
9.5 .2018\end{array}$} & 18:15 & 19:15 & $\begin{array}{l}\text { Mitgliederversammlung der Deutschen Gesellschaft für Interventionelle Radiologie und } \\
\text { minimal-invasive Therapie (DeGIR) }\end{array}$ \\
\hline & 18:15 & 19:15 & Gründung des Forums Junge Radiologen (RAD4U) \\
\hline \multirow{2}{*}{$\begin{array}{l}\text { Donnerstag } \\
10.5 .2018\end{array}$} & $17: 30$ & 19:30 & Mitgliederversammlung der Deutschen Röntgengesellschaft (DRG) \\
\hline & $13: 30$ & $14: 30$ & Mitgliederversammlung der Vereinigung Medizinisch-Technischer Berufe in der DRG (VMTB) \\
\hline $\begin{array}{l}\text { Freitag } \\
11.5 .2018\end{array}$ & 17:00 & 18:00 & Mitgliederversammlung des Forums Niedergelassener Radiologen in der DRG (FuNRad) \\
\hline
\end{tabular}

\section{Mitgliederversammlungen der AGen der DRG}

Zur ordentlichen Mitgliederversammlung der unten aufgeführten Arbeitsgemeinschaften der Deutschen Röntgengesellschaft, Gesellschaft für Medizinische Radiologie e. V. (DRG), lädt der jeweilige Vorstand die Mitglieder der jeweiligen Arbeitsgemeinschaften hiermit herzlich ein.

\begin{tabular}{|c|c|c|c|}
\hline \multirow[t]{2}{*}{$\begin{array}{l}\text { Mittwoch } \\
9.5 .2018\end{array}$} & $15: 45$ & $16: 45$ & $\begin{array}{l}\text { Mitgliederversammlung der AG Diagnostische Radiologie arbeits- und umweltbedingter } \\
\text { Erkrankungen (AG DRauE) }\end{array}$ \\
\hline & 18:15 & 19:15 & Mitgliederversammlung der AG Herz- und Gefäßdiagnostik \\
\hline \multirow{2}{*}{$\begin{array}{l}\text { Donnerstag } \\
10.5 .2018\end{array}$} & $12: 45$ & $13: 45$ & Mitgliederversammlung der AG Physik und Technik (APT) \\
\hline & $12: 45$ & $13: 45$ & Mitgliederversammlung der AG Onkologische Bildgebung \\
\hline \multirow{4}{*}{$\begin{array}{l}\text { Freitag } \\
11.5 .2018\end{array}$} & $12: 45$ & 13:45 & Mitgliederversammlung der AG Thoraxdiagnostik \\
\hline & $12: 45$ & $13: 45$ & Mitgliederversammlung der AG Ultraschall (AGUS) \\
\hline & $17: 30$ & $18: 30$ & Mitgliederversammlung der AG Pädiatrische Radiologie \\
\hline & $17: 45$ & $18: 45$ & Mitgliederversammlung der AG Kopf/Halsdiagnostik \\
\hline
\end{tabular}

